\title{
ECCOMAS
}

Proceedia

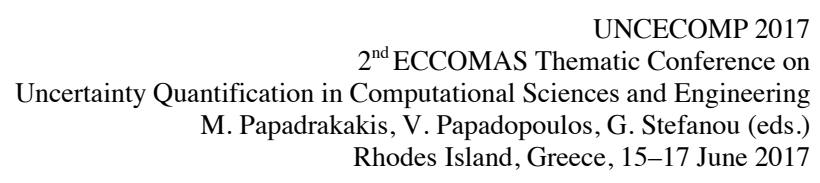

\section{FLOOD RISK ASSESSMENT OF MASONRY ARCH BRIDGES}

\author{
Enrico Tubaldi ${ }^{1}$, Lorenzo Macorini ${ }^{1}$, and Bassam Izzuddin ${ }^{1}$ \\ ${ }^{1}$ Imperial College London \\ Department of Civil Engineering, South Kensington Campus, London, SW7 2AZ. \\ e-mail: \{e.tubaldi,l.macorini,b.izzuddin\}@imperial.ac.uk
}

Keywords: Flood risk assessment, Arch Bridges, Scour, Hydrodynamic forces, Buoyancy

\begin{abstract}
Floods are one of the most common natural disasters in Europe, responsible for the damage and collapse of many masonry arch bridges built over rivers and canals. The accurate prediction of the safety of these bridges against flood-induced loading is a task of paramount importance for their preservation. This paper describes the framework developed by the authors for the flood risk assessment of masonry arch bridges, accounting for the specific characteristics of the analysed structures, the most critical types of loading associated with floods, and the various sources of uncertainty relevant to the problem. The proposed framework combines the results of flood hazard analysis and of structural vulnerability analysis to obtain the flood risk estimate. A case study consisting of a three-span bridge under scour is considered to illustrate the application of the proposed framework and to show the capabilities of the advanced modelling technique developed for evaluating the effects of flood actions on masonry arch bridges.
\end{abstract}




\section{INTRODUCTION}

Masonry arch bridges still constitute a significant portion of the bridge stock in Europe [1][3]. These structures have proven to be very durable, with a service life extending well beyond the design life of modern bridges. However, the combined effects of ageing/deterioration, scarce maintenance as well as the increase of traffic loading and natural/man-made hazards have resulted in a significant growth of their risk of failure. In particular, many masonry arch bridges are built on over rivers and canals, which make them very vulnerable to flood effects. These include [4]: a) hydrodynamic pressure on the submerged surfaces exerted by the water and floating debris, b) buoyant forces on the submerged components, and c) scour at the footings of piers and abutments, which is the most common cause of collapse due to the high vulnerability of arches to foundation settlements. Despite the high rate of failure of masonry arch bridges due to floods, studies on this topic are rather scarce, and cover only specific aspects of the problem [5]-[9]. To account for the joint effect of floodinduced actions on bridges, a probabilistic approach is required given the randomness in the occurrence and magnitude of floods, and the uncertainty in the models employed to predict flood effects.

This paper illustrates the framework developed for the flood risk assessment of masonry arch bridges. This framework accounts for the specific characteristics of the analyzed structures, the most critical types of loading associated with floods, and the various sources of uncertainty relevant to the problem. It aims to overcome current approaches for flood risk assessment which consider only a design flood event with a given return period to estimate the bridge safety [10].

In the first part of the paper, the various steps of the framework and the inherent assumptions are explained, together with the extension to account for the temporal accumulation of scour. The application of the framework to masonry arch bridges also involves the development of accurate and efficient computational modelling strategies to evaluate the effect of flooding. In this regard, an accurate three-dimensional (3D) mesoscale representation [11] of masonry arch bridges has been developed at Imperial College [12]-[16]. The proposed modelling approach allows for a realistic description of the non-homogeneous components of masonry arch bridges and the three-dimensional behaviour induced by the flood-induced actions. In the final part of the paper, a realistic case study is considered to show the application of the proposed framework to the risk assessment of masonry arch bridges under scour, which is the most critical action due to floods.

\section{FRAMEWORK FOR FLOOD RISK ASSESSMENT}

\subsection{Flood-induced actions}

Water flow exerts different actions on arch bridges. First of all, it induces a significant hydrodynamic pressure on the submerged surfaces, resulting in horizontal forces which may become very high when the deck is also submerged [7],[8]. Foundation capacities decrease when the water level increases due to the increased eccentricity of the vertical loads. Buoyant forces reduce the effective unit weights of submerged components, thus decreasing the loadcarrying capacity of the bridge which strongly depends on the compressive forces within the arch due to the self-weight [5]. Large floating lumps/debris can impact the bridge causing local damage which can jeopardize the bridge integrity. Water flow results also in scour at the footings of piers and abutments which is the most common cause of collapse due to the high vulnerability of arches to foundation settlements [17][18]. The factors causing scour to develop are complex and differ according to the type of structure. Scour may occur as a result of 
natural changes of flow in the channel, as part of longer-term morphological changes to the river, or as a result of human activities, such as the building of structures in the channel or the dredging of material from the bed. Undermining the foundation can induce several negative effects which may jeopardize the integrity of arch bridge components or even global stability. These include (i) rupture of the foundation plinth due to the loss of support [19], (ii) failure of the foundation-soil system [20], (iii) cracking and mechanism formation due to angular rotation, (iv) subsidence, and/or (v) shift of the bridge pier's [21]. Finally, it is worth noting that the low clearance offered by arch bridges makes them very susceptible to debris accumulation, and this may increase both scour development and hydrodynamic forces [22].

The evaluation of the performance of bridges against floods must account for the random nature of flood-induced actions. This entails the development of a probabilistic hazard model capable of describing the frequency of exceedance of the intensity of the single actions as well as their correlation. The model should also account for the fact that flood-induced actions on bridges may often concurrently interact with each other, e.g. the accumulation of debris against bridges might significantly affect the bridge hydraulics, the hydrodynamic forces and the scour at the bridge foundations, as well as the development of a scour hole may increase the hydrodynamic pressure on the bridge.

\subsection{Framework description}

The proposed framework is very similar in concept to other frameworks that have been recently formalised for evaluating the risk of structures exposed to different natural and manmade scenarios including blast, fire, tsunami and wind scenarios [23]-[25]. The main aim of these methodologies is to provide a general procedure for the evaluation of the performance of structural systems in terms of decision variables (DVs) such as risk of collapse, fatalities, repair costs, and loss of function, while accounting for all the possible sources of uncertainty that characterise the problem at hand. In this way, the structural risk can be efficiently defined in terms of variables of interest for stakeholders, decision makers, and the society.

The flood risk assessment framework disaggregates the performance assessment procedure for bridge structures subject to the flood hazard into elementary tasks that are carried out in sequence. In particular, the risk assessment is disaggregated into: (1) hydrologic analysis, (2) hydraulic analysis, (3) interaction analysis, (4) structural analysis, (5) damage analysis, and (6) loss analysis (Fig.1). The following expression is used to integrate the results of these tasks:

$$
\begin{gathered}
\lambda_{D V}=\iint_{q} \int_{h} \int_{i p} \int_{\text {edp }} G_{d m} G_{D V \mid D M}(d v \mid d m) \cdot f_{D M \mid E D P}(d m \mid e d p) \cdot f_{E D P \mid I P}(e d p \mid i p) \cdot f_{I P \mid H, Q}(i p \mid h, i m) \\
\cdot f_{H \mid Q}(h \mid i m) \cdot d D M \cdot d E D P \cdot d I P \cdot d H \cdot\left|d \lambda_{I M}(i m)\right|
\end{gathered}
$$

where $G(\bullet)=$ complementary cumulative distribution function, and $G(\bullet \bullet)=$ conditional complementary cumulative distribution function; $f(\bullet)=$ probability density function, and $f(\bullet \bullet)=$ conditional probability density function; $I M=$ vector of intensity measures (i.e., parameters characterizing the environmental hazard); $S P=$ vector of structural parameters (i.e., parameters describing the relevant properties of the structural system and non-environmental actions); $I P=$ vector of interaction parameters (i.e., parameters describing the interaction phenomena between the environment and the structure); $E D P=$ vector of engineering demand parameters (i.e., parameters describing the structural response for the performance evaluation); $D M=$ vector of damage measures (i.e., parameters describing the physical damage to the structure), $D V=$ vector of decision variables. 


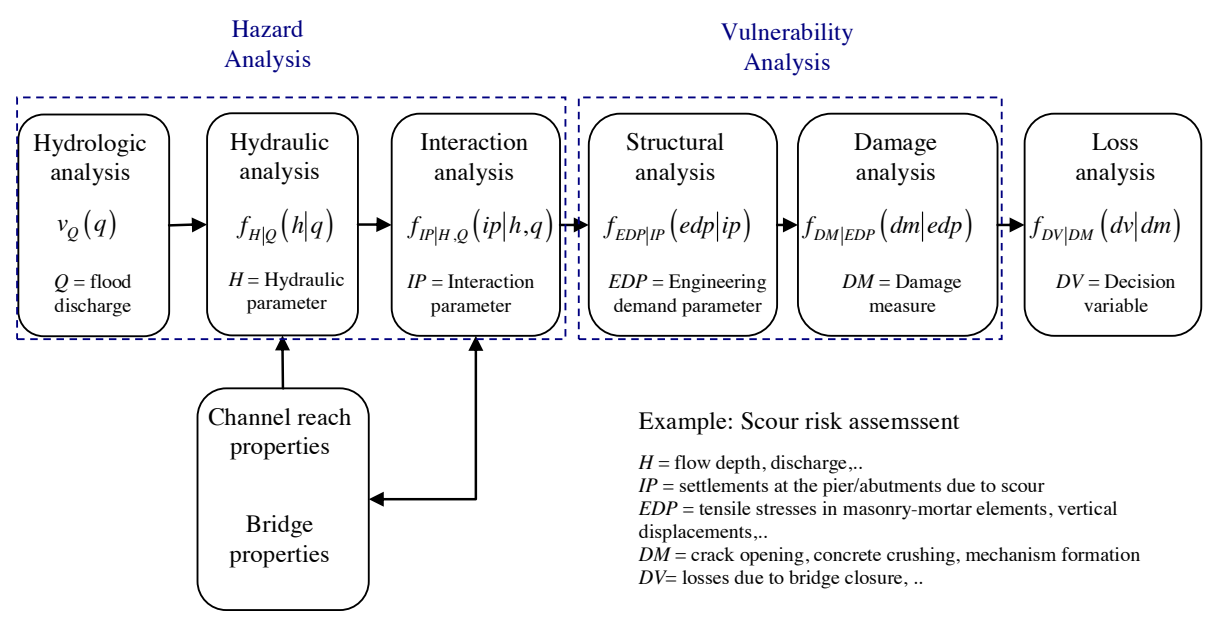

Fig. 1. Illustration of the risk assessment framework.

It is worth noting that this decomposition, which is a statement of the Total Probability Theorem, is made possible through the fundamental Markovian assumption that the result of each analysis (e.g. $D V$ ), conditional on the result of the previous step (e.g. $D M$ ), is independent from the other preceding steps of the analysis (i.e., EDP, $I P, H, I M)$. Another assumption that needs to be introduced is that of stationarity, i.e. the conditional probabilities are the same and the relevant conditional distributions shown in these formulas are independent and identically distributed for successive flood events. This implicitly assumes that the system does not deteriorate/evolve, and that it is instantaneously restored to its original state after each flooding event. In this regard, it should be observed that while the hydrodynamic and buoyancy actions associated with the flood event can be assumed to renew at each flood occurrence by following the same conditional probability distribution, the scouring can be cumulative over the long term, and it may result by the succession of events of flooding of different intensity occurring over time.

The combination of the first steps (1)-(3) of the framework allows the characterisation of the flood hazard in terms of the mean annual frequency (MAF) of exceedance for the IPs that are used as input for the structural analysis such as the hydrodynamic pressure, the buoyancy and the extent of the scour. Under the aforementioned assumption, it can be shown that also the IPs follow a Poisson distribution with a mean rate given by the combination of the results of steps (1)-(3). The combination of the results of steps (4)-(5) provides information on the structural vulnerability. This can be expressed in terms of fragility curves, which yield the probability of exceeding given damage or limit states vs. the values assumed by the IPs.

\subsection{Incorporation of memory effects in scour risk assessment}

As already pointed out in the previous section, scouring can accumulate during successive events, and it may take many events before the maximum scour depth is fully developed. The temporal evolution of scour depends on whether it occurs under so called clear water or live bed conditions. The former case occurs when the velocity of the flow upstream of the bridge is lower than the critical velocity necessary to erode the river bed, whereas the latter when it is higher [26]. Thus, in clear water conditions, erosion processes occur only in proximity of bridge foundations whereas in live-bed conditions sediment transport occurs in the undisturbed channel upstream of the bridge. In live-bed conditions the scour hole is continually supplied with sediment by the approach flow. In the clear-water scenario, the equilibrium scour depth is approached asymptotically when the flow is no longer capable of removing bed 
sediment from the hole. In the live-bed scenario, an equilibrium is attained when, over a period of time, the average amount of sediment transported into the scour hole by the approach flow is equal to the average amount of sediment removed from the scour hole due to erosion processes. Generally, scour holes develop more slowly under clear water conditions, for which the equilibrium scour depth is reached asymptotically. Under live-bed conditions, equilibrium is reached much faster. Contrary to the clear-water case, in live-bed conditions the scour hole tends to be refilled with sediment as the flood recedes. More research is however needed to characterize this phenomenon.

In order to illustrate these concepts, Fig. 2 shows a sample of a flood hydrograph of a channel and the corresponding evolution of the scour depth at the foundation of a bridge pier. The flow in the channel is such that live bed conditions are attained only during the time interval $\left[t_{3}, t_{4}\right]$, while clear water conditions are observed during many time intervals. For example, during $\left[t_{0}, t_{1}\right]$, the scour depth increases under clear water conditions, at a rate which is higher during the ascending part of the flood hydrograph and very low during the receding limb. In the time interval $\left[t_{1}, t_{2}\right]$, the scour depth does not increase because the discharge is below the level $q_{0}$ necessary to induce scour, in $\left[t_{2}, t_{3}\right]$ it increases again under clear water conditions. Finally, in $\left[t_{3}, t_{4}\right]$ the scour evolves under live-bed conditions, and the scour hole is partially refilled with sediment from upstream the bridge.

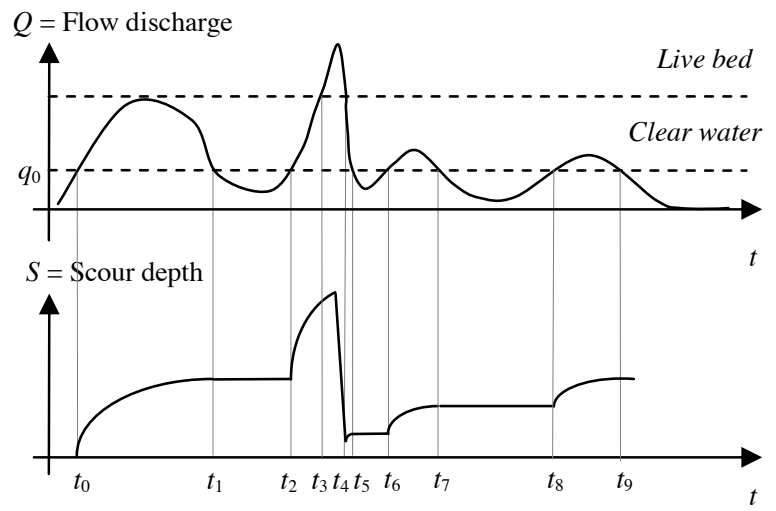

Fig. 2. Flow chart illustrating the probabilistic framework for scour risk assessment.

While the process described above is only qualitative, it suggests a different analytical treatment of the problem for clear water and live-bed scour. For floods of high intensity, presumably inducing live-bed scouring conditions, it is plausible to assume that the equilibrium scour depth is attained almost instantaneously, followed by a recession stage with refilling. Thus, the probability of exceeding the critical scour depth depends only on the flow discharge (and the relevant values of the hydraulic parameters) of that particular flood event rather than on the history of scour evolution. For floods of lower intensity and hence presumably inducing clear water scouring conditions, a single flood event is unlikely to induce a critical scour depth, but it may only deepen the scour hole. The repeated occurrence of multiple floods may however still result in the attainment of the critical scour depth, with an associated probability which increases by increasing the number of floods, their intensity and duration [27]. Thus, in this case it is very important to account for memory effects.

One way to account for memory effects in evaluating the probabilistic distribution of the scour depth is to assume that the susceptibility to increase (or eventually decrease) scour during one event, given the features of the flood, depends on the scour level accumulated until the occurrence of the event itself, rather than on the entire flood and scour history. This leads to a Markov-process description [28] of the scour evolution process. 
Hereinafter, the methodology developed by the authors [29] to account for memory effects is illustrated synthetically. Let $P_{n}(t)$ denote the number of floods occurring in $[0, t]$ of intensity higher than a minimum significant threshold, and $P_{i}^{0}$ the probability mass function of the scour depth at year 0 . A set of discrete scour states of increasing scour depth is assumed, and the probability of the scour depth $S$ being equal to $s_{j}$ at time $t$ can be expressed as:

$$
P_{j}(t)=\sum_{n=0}^{\infty} \phi_{i j}^{n} P_{i}^{0} \cdot P[N=n]
$$

where $\boldsymbol{\Phi}=\left[\phi_{i j}\right]$ is the state transition matrix, expressing the probability of passing from scour state $i$ to scour state $j$ given the occurrence of an event of a given significant magnitude, and $P[N=n]$ is the probability of having a number $n$ of events of intensity higher than the minimum threshold. Obviously, $\boldsymbol{\Phi}$ must be derived by accounting for the randomness in the flood intensity and the actual duration of each flood. Given an hazard model, Monte Carlo simulation can be employed to estimate $\boldsymbol{\Phi}$. Once $\boldsymbol{\Phi}$ and $P_{i}^{0}$ are known, the first passage probability of exceedance for the scour depth can be evaluated.

\section{MESCOSCALE PARTITIONED MODELLING OF MASONRY ARCH BRIDGES}

This section describes the advanced modelling strategy developed for the analysis of masonry arch bridges based on the mesoscale partitioned modelling approach proposed in [12], [13]. This approach has been developed specifically for computation of large-scale unreinforced masonry structures, and it has been already employed and validated for evaluation of arches and single-span masonry arch bridges subjected to vertical loadings and settlements [14],[15].

Masonry is a heterogeneous and strongly nonlinear material whose behaviour depends on the orientation of the loading direction with respect to the masonry bond, where mortar joints represent preferential fracture planes [30]. In this respect, a detailed mechanical model for the masonry arch and piers should take into account not only the mechanical characteristics of units and mortar but also the actual 3D masonry texture. Unlike continuous approaches which assumes masonry a homogeneous material, a discrete modelling strategy [12] is employed to represent the actual masonry bond and model the development of cracks in real brick/stonemasonry arches and in the masonry piers. This numerical strategy allows for an accurate representation of the 3D domain of any masonry arch/pier, as the actual 3D masonry bond is represented using two or more elastic solid elements for each brick and 2D nonlinear interface element for mortar joints. In particular, 20-noded elastic solid elements formulated according to standard finite element (FE) procedures are used together with specific 2D zero-thickness nonlinear interface elements with 16 nodes accounting for material and geometric nonlinearity. In this way, the typical fracture lines which characterise the nonlinear response up to collapse of masonry arches can be represented. These correspond to radial cracks, circumferential cracks leading to ring separation in multi-ring arches and longitudinal cracks caused by transverse bending. While the first two types of crack generally take place in the mortar joints, longitudinal cracks may pass also through the masonry units. Thus nonlinear interface elements are placed also in the middle of each brick to capture the potential development of cracks. This renders the FE mesh for brick-masonry arches relatively simple, as it is made up of identical solid elements connected to each other by nonlinear interface elements as shown in Fig. 3. In the constitutive model for the adopted interface element, material nonlinearity is 
taken into account by employing a cohesive model, which enables an effective representation of damage, cracks and plastic separations. More detailed information can be found in [13].
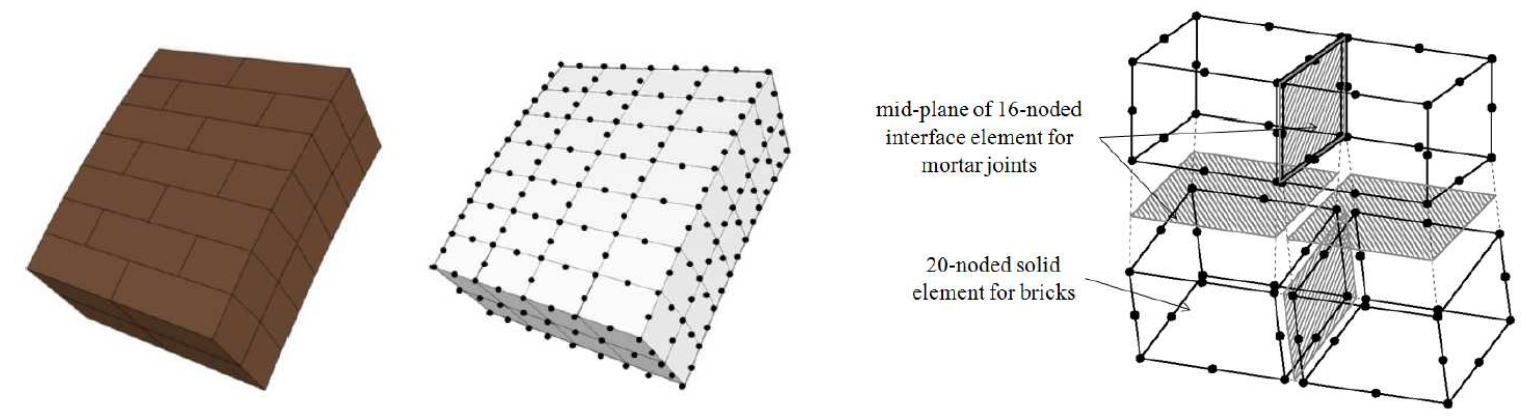

Fig. 3. (a) 3D mesoscale model for masonry arches, (b) Solid elements connected by nonlinear interfaces.

A realistic representation of the fill behaviour and its interaction with the arch barrel is critical for an accurate response prediction of masonry arch bridges. In the proposed modelling strategy, similarly to other studies on masonry arch bridges [18], the backfill is described as a continuous elasto-plastic material, where a Drucker-Prager plastic criterion with tension cut-off [31] is adopted to describe the development of plastic deformations. In particular, 15noded elasto-plastic tetrahedral elements are utilised to model the fill domain.

With reference to the foundations and the soil, masonry arch bridges are often built on shallow foundations [32],[33], making them very vulnerable to scour. In order to simulate accurately the scour effects, the bridge model should also include the foundation and the surrounding soil domain. The soil medium has a very complex mechanical behaviour, which is generally nonlinear, stress-dependent, anisotropic and heterogeneous in nature. The difficulty to simulate these features may outweigh the advantages of using complex modelling approaches. For this reason, in order to investigate the effects of scour, a Winkler subgrade modelling approach is adopted in this study, where the three-dimensional soil domain is replaced by a set of interfaces surrounding the foundation. The soil interfaces can resist only normal forces and are characterized by a linear elastic behaviour with a coefficient of subgrade reaction $k_{s}$, relating deflection (settlement) and soil pressure [34]. Different formula can be employed for estimating the values of the subgrade parameters. In this study, references is made to the expressions developed by Gazetas [35], reported in [36] in function of the shear modulus of the soil $G_{\mathrm{s}}$ and of the foundation geometry. Fig. 4 shows a model of a two span masonry arch bridge, including the backfill, the spandrel walls, and the foundation with the surrounding interfaces.

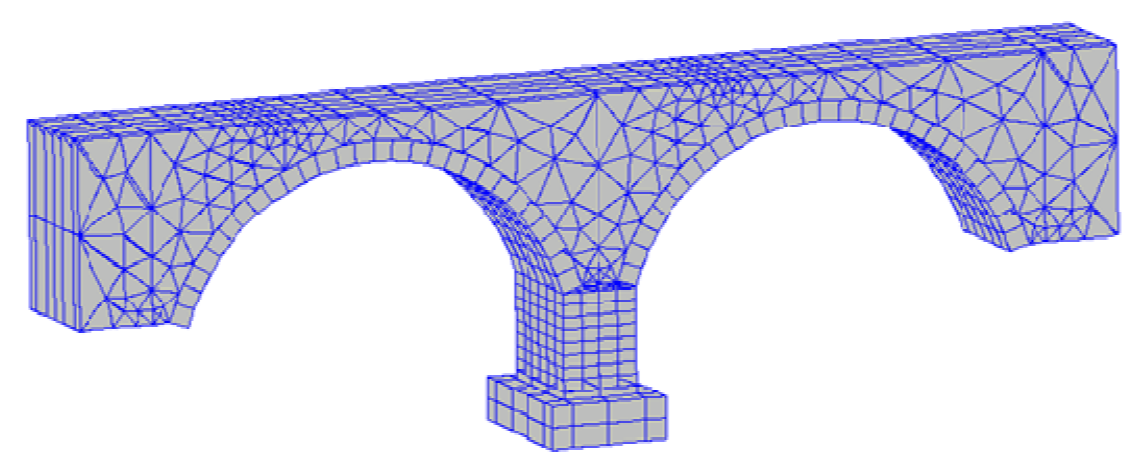

Fig. 4. Bridge-foundation-soil model with soil modelled via Winkler-type interfaces. 
The hierarchical partitioned modelling method [37],[38], available in the FE code ADAPTIC [39], is employed to minimize the computational cost of the analyses. This approach consists in dividing the structure into super-elements, with each super-element corresponding to one partition. The connection between the different hierarchical levels is achieved by ensuring that the number of element nodes connected to the parent structure is equal to the number of nodes at the partition boundary in the corresponding partition. Each partition is then modelled using the mesoscale approach described earlier and the parent structure corresponds to the partitioned boundary. Dual super-elements allow for partitions to be modelled as separate processes, where communication between each parent/child superelement pair ensures that the analysis for all partitions is run in parallel. A pre-processor has been developed in Matlab to automate the generation and partitioning of the bridge model for ADAPTIC, by accounting for the actual texture and arrangement of the masonry bricks.

\section{CASE STUDY}

This section presents a case study, where the proposed flood risk assessment framework is applied to evaluate the scour risk for a realistic two-span bridge. The focus here is on pier scour, which is one of the most critical flooring actions, whose modelling has not received adequate attention to date.

\subsection{Bridge and numerical model description}

The analysed structure is a two-span arch bridge with a length of $20.30 \mathrm{~m}$ (left to right abutment) and a width of $3.80 \mathrm{~m}$. The two arches are segmental in shape, with a radius of $9.26 \mathrm{~m}$, a rise of $3.45 \mathrm{~m}$, and a thickness of $0.50 \mathrm{~m}$. The pier is cylindrical with diameter $D=2 \mathrm{~m}$. Fig. 5 reports a schematic illustration of the bridge.

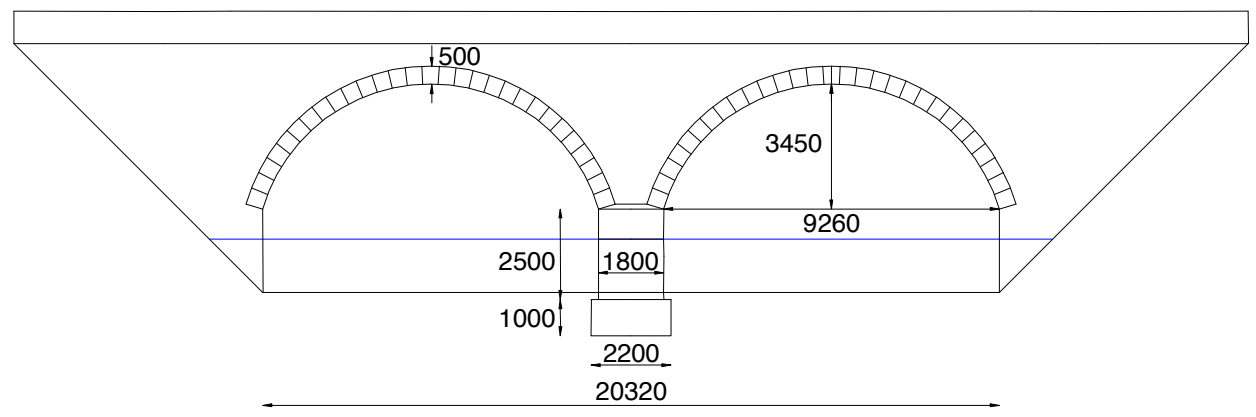

Fig. 5. Schematic illustration of the bridge (dimensions in $\mathrm{mm}$ ).

The river in proximity of the bridge is assumed to have a trapezoidal section, with base $B=$ $20.32 \mathrm{~m}$, a riverbank slope (vertical over horizontal) of $1 / 3$, a channel slope $S_{0}=0.0006$. The river bed is composed of sand with relative density $\gamma=16.5 \mathrm{kN} / \mathrm{m}^{3}$ and uniform diameter $D_{50}$ $=2 \mathrm{~mm}$, corresponding to a Manning coefficient $n=0.035 \mathrm{~s} / \mathrm{m}^{1 / 3}$. The friction angle of the bed material is taken equal to $30^{\circ}$.

The flood occurrence is described by a homogenous Poisson process, with a mean annual frequency of occurrence of flood events of peak discharge $\mathrm{Q}>q_{0}=10 \mathrm{~m}^{3} / \mathrm{s}$ equal to $\lambda=2 \mathrm{yrs}^{-1}$. The peak flood discharge $Q$ for a given event is assumed to follow an exponential distribution, with scale parameter $\beta=25 \mathrm{~m}^{3} / \mathrm{s}$ and $q_{0}=10 \mathrm{~m}^{3} / \mathrm{s}$. For simplicity, a triangular shape is assumed for the flood hydrograph, with a duration in hours described by the relation 
$t_{\text {hyd }}(q)=0.63\left(q-q_{0}\right)$ [40]. According to this relationship, the flood duration increases linearly with its peak discharge and it assumes a value equal to 5 days for $q=200 \mathrm{~m}^{3} / \mathrm{s}$. The hydraulic properties of the flow for the different discharge values are evaluated in a simplified way through the Manning formula.
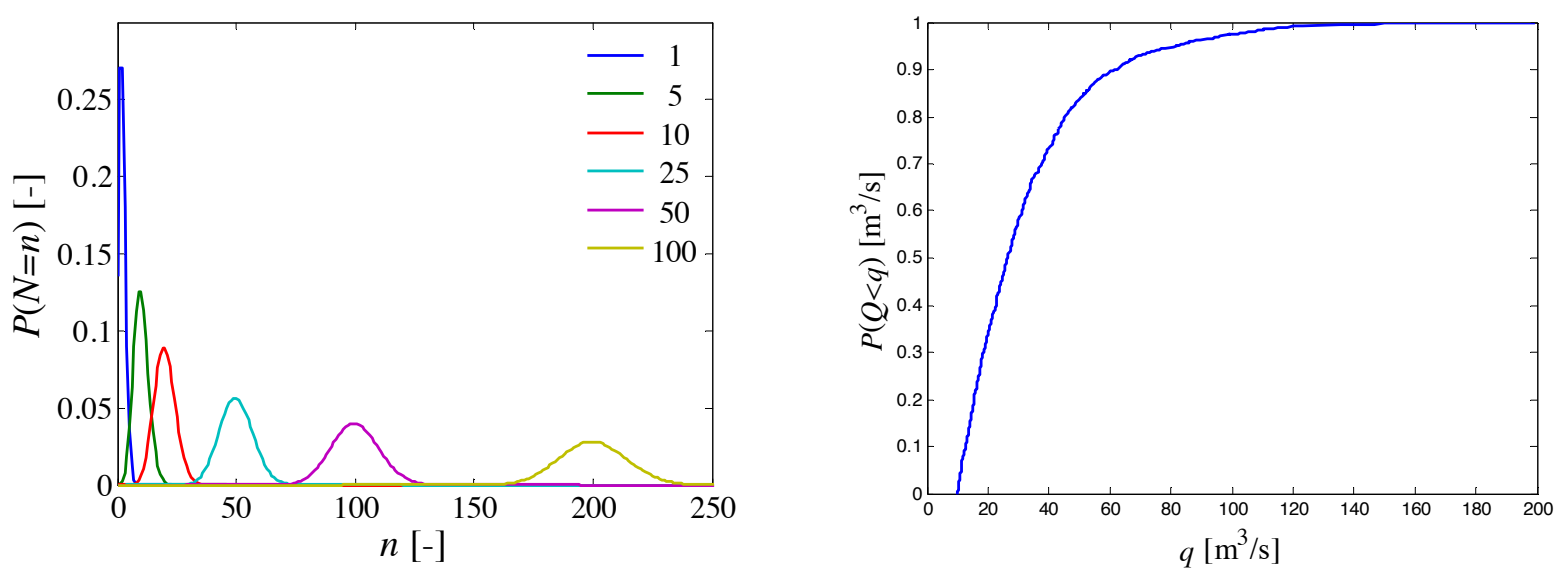

Fig. 6 a) Probability mass function of the number $N$ of occurrences of flood events with $Q>q_{0}$ for different design life times, b) Empirical cumulative distribution function of the flow discharge for a given flood event of magnitude $Q>q_{0}$.

\subsection{Scour risk assessment}

This section illustrates some preliminary results of the analyses carried out to evaluate the probability of bridge collapse under scour. The vulnerability analysis of the bridge against scour is carried out for the collapse limit state, which is analytically defined as $G=R-S$, where $R$ denotes the value of the scour depth that induces collapse of the bridge under the permanent loads, and $S$ is the scour depth.

The value of $S$ is evaluated by following the procedure outlined in Section 2.3, assuming that the initial scour depth is known deterministically and equal to 0m. Fig. 7a,b show respectively the empirical probability mass function of the scour depth and the risk of exceedance of the scour depth at different times of observation between 0 and 100 yrs. The probabilistic distribution of the scour depth evolves in time by exhibiting an increase of the mean value of $S$, and a decrease of standard deviation. In fact, the scour depth $S$ slowly tends to a stationary value which is attained ideally for an infinite time of observation.
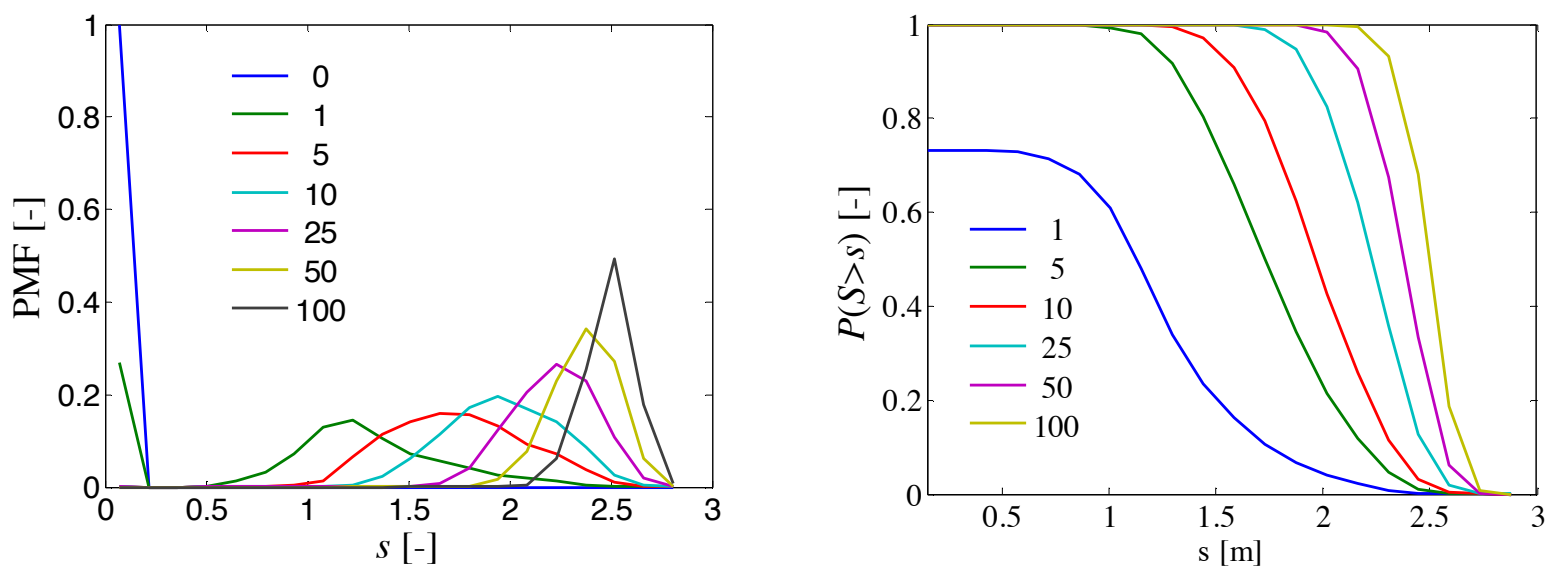

Fig. 7 Probability mass function and risk of exceedance of the scour depth at different times (between $1 \mathrm{yr}$ and 100 yrs after the initial one. 
It is noteworthy that the value of $S$ represents here the maximum depth of the hole created by scouring. The geometric domain of the scour hole is defined by an inverted pyramid. The upstream surface has a slope corresponding to an angle equal to the soil friction angle $\left(\phi=30^{\circ}\right)$, the downstream one has a slope corresponding to $\phi / 2$, whereas the lateral surfaces have a slope corresponding to $3 / 4 \phi$. The maximum scour depth is assumed to be located along the vertical plane containing the upstream pier surface.

The value of $R$ is evaluated by performing the structural analysis on the FE bridge model under progressively increasing scour depths. The mechanical properties of the model are representative of typical bridge constructions [14],[42]. In particular, a tensile strength $\sigma_{t 0}=$ $0.06 \mathrm{MPa}$, a cohesion $c_{0}=0.1 \mathrm{MPa}$ and a friction angle with tangent $\tan (\phi)=0.75$ were considered for the mortar joints, while a Young's Modulus $E_{b}=3918 \mathrm{MPa}$ and a Poisson's ratio $v_{b}=0.15$ were utilised for the brick units. The compressive strength of masonry is assumed equal to $\sigma_{c 0}=8 \mathrm{MPa}$. The backfill material model has a friction angle of $\phi_{b f}=60^{\circ}$, a dilation angle of $\phi_{b f d}=30^{\circ}$, and a cohesion $c_{b f}=0.01 \mathrm{MPa}$. The elements describing the spandrel walls are assigned a value of the Young modulus $E_{w}=3100 \mathrm{MPa}$, a cohesion $c_{w}=0.1 \mathrm{MPa}$, a friction angle $\phi_{w}=43^{\circ}$, a dilation angle $\phi_{w d}=10^{\circ}$, and a tensile cap on the first invariant of stress tensor $I_{w t}=0.03 \mathrm{Mpa}$. The compressive strength is assumed equal to $\sigma_{c 0}=8 \mathrm{MPa}$. Finally, the riverbed sand is assumed to have a Young's Modulus $E_{r}=500 \mathrm{MPa}$ and a Poisson's ratio $v_{r}=$ 0.15 , leading to a normal stiffness of the interfaces below the foundation equal to $k_{v}=$ $0.184 \mathrm{~N} / \mathrm{mm}^{3}$.

The scour action is simulated via time-history analysis by progressively degrading the stiffness of the interfaces representing the soil and located within the scour hole. Fig. 8 shows the evolution of the scour hole and the progressive removal of the interfaces located within the scour hole.
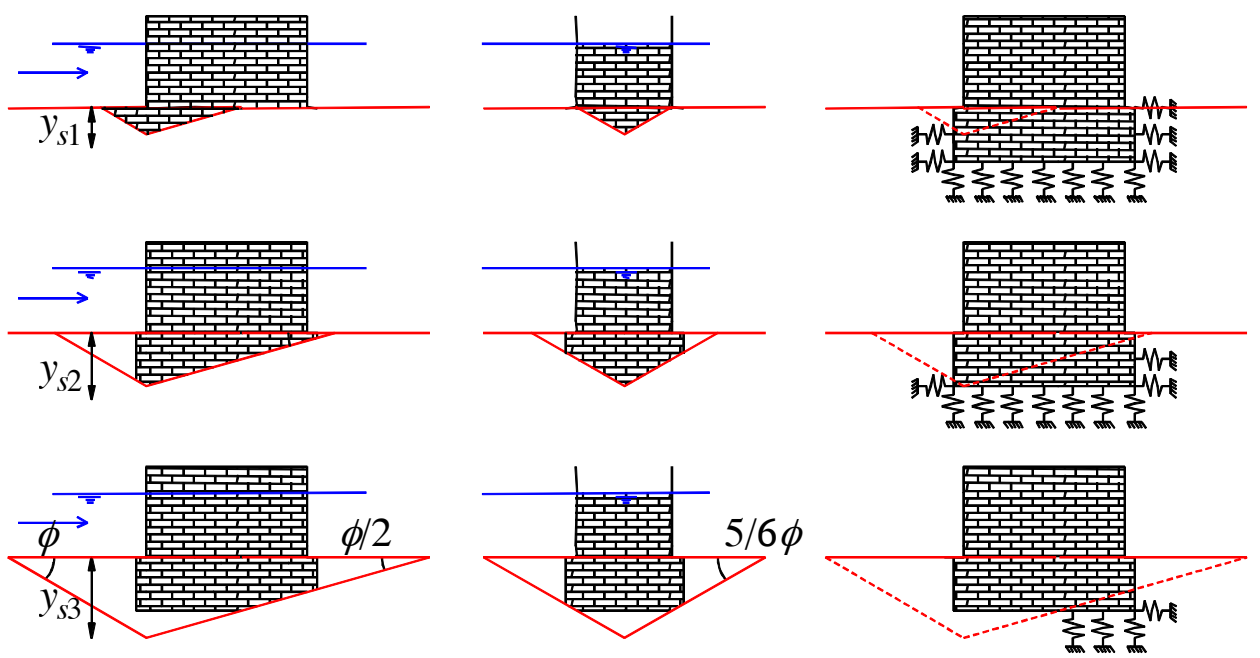

Fig. 8. Assumed scour hole shape and scour progression modelling.

Fig. 9 shows the deformed shape of the bridge at different increasing scour levels. The scour action induces a rotational mechanism at the base of the pier, with non-uniform vertical displacements along the pier base, and a formation of a crack between the foundation and the pier. This mechanism has been responsible of the collapse of Copley Bridge, a two-span bridge located near Halifax, West Yorkshire, whose geometrical properties are very similar to those of the model considered as case study. Fig. 10 shows the cracks in the arch barrel for a 
maximum scour depth $s=2.6 \mathrm{~m}$, and Fig. 11 shows the damage in tension of the mortar interfaces between the bricks. It can be observed that scour induces the formation of both transversal and diagonal cracks in the arch barrel. The diagonal cracks are located in proximity of the pier and of the abutments, whereas the transversal cracks are localized at midspan of each span. When the maximum scour depth attains the value $s=2.6 \mathrm{~m}$, the extent of cracking is very significant and the bridge is at collapse. The corresponding risk of failure, based on Fig. $7 \mathrm{a}$, is established as $2 \%$ in 100 years.

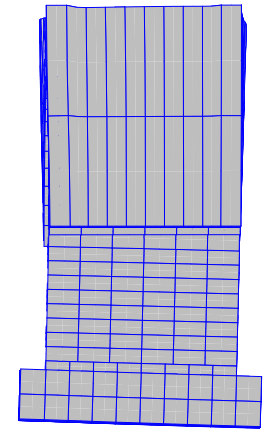

$s=2.3 \mathrm{~m}$

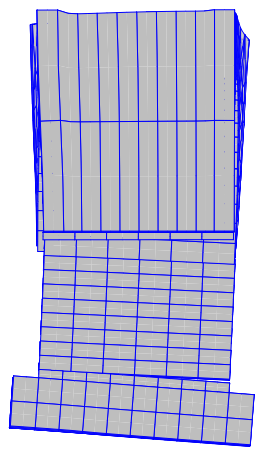

$s=2.4 \mathrm{~m}$

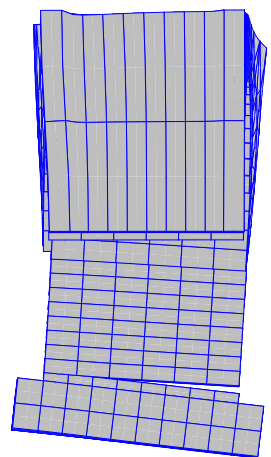

$s=2.49 \mathrm{~m}$

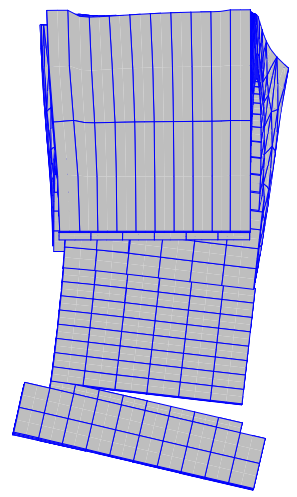

$s=2.6 \mathrm{~m}$

Fig. 9. Deformed shape of the bridge model for increasing levels of maximum scour depth.

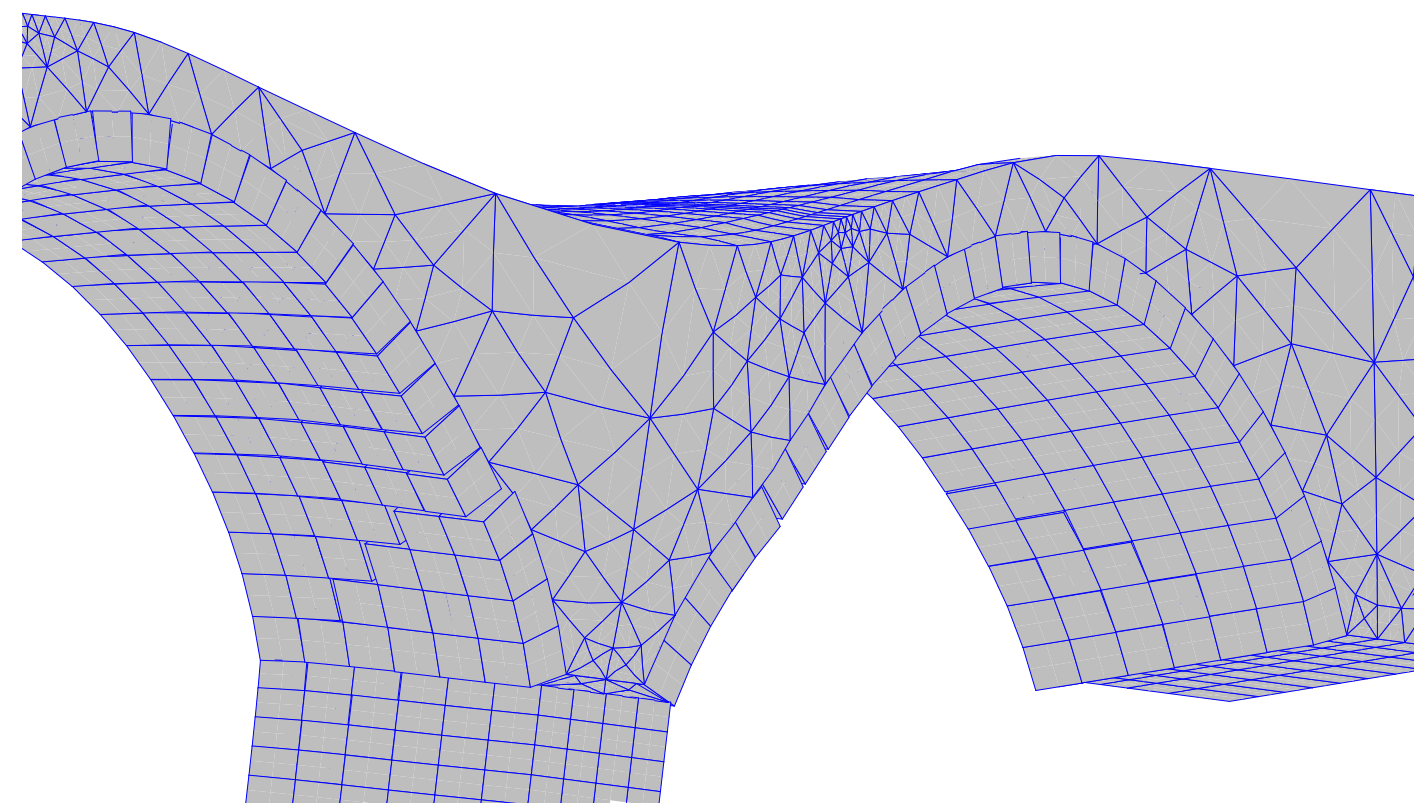

Fig. 10. Cracking patter in the arch barrel for maximum scour depth $s=2.6 \mathrm{~m}$.
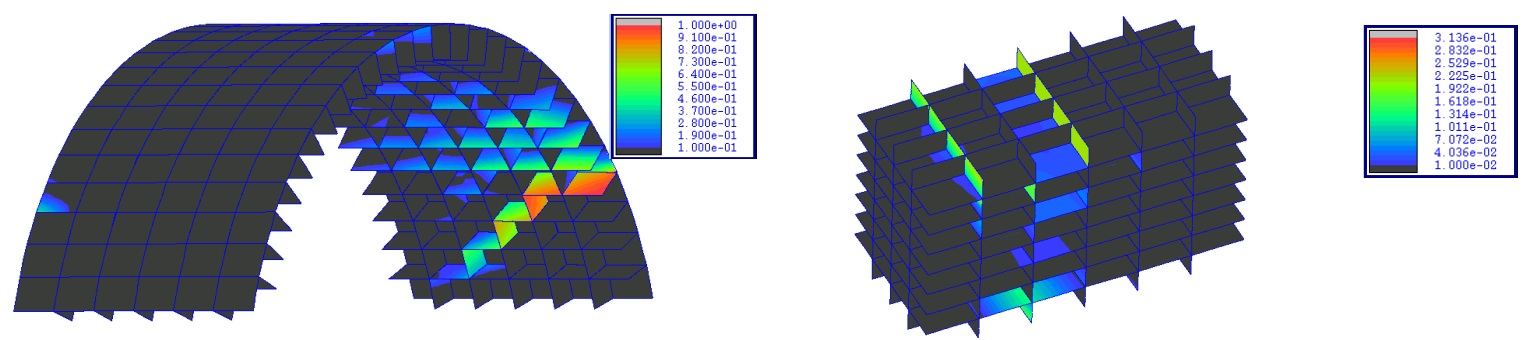

Fig. 11. Damage parameter in tension in the arch and the pier for maximum scour depth $s=2.6 \mathrm{~m}$. 


\section{CONCLUSIONS}

In this paper, a probabilistic framework for the flood risk assessment of masonry arch bridges is illustrated. The framework integrates information on the most critical actions associated with the flood hazard analysis with those of structural vulnerability analysis. The computational strategy developed by the authors for the numerical analysis of the structural response of masonry arch bridges subjected to flooding actions is also described.

The proposed framework and modelling strategy are applied to the scour risk assessment of a realistic case study. It is shown that an accurate 3D model, including the foundation and the surrounding soil, can be used to describe the rotational-translational mechanism induced by the scour action at the base of the pier, allowing the prediction of cracks forming in the pier and arches. Future studies will address the impact of other critical actions induced by floods on masonry arch bridges, the influence of the uncertainty of the model parameters on the risk estimates, and also the development of simplified and efficient modelling strategies leading to a reduction of the computational cost.

\section{AKNOWLEDGEMENTS}

The financial support of the European Commission through the Marie Skłodowska-Curie Individual fellowship IF ("FRAMAB", Grant Agreement 657007) for the first author is greatly acknowledged. The authors also acknowledge the High Performance Computing (HPC) Services at Imperial College for providing and supporting the required computing facilities.

\section{REFERENCES}

[1] Z. Orbam, UIC Project on Assessment, Inspection and Maintenance of Masonry Arch Railway Bridges. ARCH'07: 5th International Conference on Arch Bridges, Multicomp, Lda Publishers, Madeira, 2007.

[2] Sustainable Bridges, Masonry Arch Bridges Background document D4.7, Sustainable Bridges EU FP6, 2007.

[3] J.R. Casas, Reliability-based assessment of masonry arch bridges. Construction and Building Materials, 25(4), 1621-1631, 2011.

[4] D. Ryan, G.A. Hamill, J. McRobert, W. Smith, The hydraulics and resulting bed scour within the vicinity of Submerged Single Span Arch Bridges, Civil Engineering Research in Ireland, Belfast, UK, 2014.

[5] K.M. Hulet, C.C. Smith, M. Gilbert. Load-carrying capacity of flooded masonry arch bridges. Bridge Engineering, 156, 97-103, 2006.

[6] M. Gilbert, Limit analysis applied to masonry arch bridges: state-of-the-art and recent developments. 5th International Conference on Arch Bridges (ARCH'07), Funchal, Madeira, Portugal, 2007.

[7] Y. Knoishi, Experimental Study on Effect of Stone Arch Bridge on Flood Flow and its Stability against Flood Pressure. Japan Society of Civil Engineers, Structural Eng./Earthquake Eng., 4(1), 61-71, 1987.

[8] M. Afraz Habibi, M.T. Ahmadi, Assessment of Masonry Arch Bridge Behaviour subject to Service and Flood Loads, Tenth international conference on computational structures technology, Civil-Comp Press, Dun Eaglais, Kippen, UK, 2010. 
[9] D. Proske, J. Hübl, Historical arch bridges under horizontal loads. ARCH 07 conference, Madeira, 2007.

[10] P.F. Lagasse, M. Ghosn, P.A. Johnson, L.W. Zevenbergen, P.E. Clopper, Reference guide for applying risk and reliability-based approaches for bridge scour prediction, NCHRP REPORT 761, Washington D.C, US, 2013.

[11] P.B. Lourenço, J.G. Rots, Multisurface interface model for analysis of masonry structures, Journal of Engineering Mechanics, 123(7), 660-668, 1997.

[12] L. Macorini, B.A. Izzuddin, Nonlinear analysis of masonry structures using mesoscale partitioned modelling, Advances in Engineering Software, 60-61, 58-69, 2013.

[13] L. Macorini, B.A. Izzuddin, A non-linear interface element for 3D mesoscale analysis of brick-masonry structures, International Journal for Numerical Methods in Engineering, 85, 584-1608, 2011.

[14] Y. Zhang, Advanced nonlinear analysis of masonry arch bridges, PhD Dissertation, Imperial College London, London, 2015.

[15] Zhang, Y., Macorini, L., \& Izzuddin, B. A. (2016). Mesoscale partitioned analysis of brick-masonry arches. Engineering Structures, 124, 142-166.

[16] E. Minga, L. Macorini, B.A. Izzuddin, Mesoscale modelling of masonry structures using mesh tying, $15^{\text {th }}$ International Conference on Civil, Structural and Environmental Engineering Computing, Civil-Comp Press, Stirlingshire, Scotland, UK, 2015.

[17] A.M. Kirby, M. Roca, A. Kitchen, M. Escarameia, O.J. Chesterton, Manual on scour at bridges and other hydraulic structures, 2nd edition, CIRIA C742 Report, 2015.

[18] G. Ruocci, Application of the SHM Methodologies to the Protection of Masonry Arch Bridges from Scour, $\mathrm{PhD}$ Thesis, Polytechnic University of Torino, Italy, 2010.

[19] D.V. Swenson, A.R. Ingraffea, The collapse of the Schoharie Creek Bridge: a case study in concrete fracture mechanics, International Journal of Fracture, 51(1),73-92, 1991.

[20] F. Federico, G. Silvagni, F. Volpi, Scour vulnerability of river bridge piers. Journal of Geotechnical and Geoenvironmental Engineering, 129(10), 890-9, 2003.

[21] J. Witzany, T. Cejka, R. Zigler, Failure resistance of the historic stone bridge structure of Charles Bridge. I: Susceptibility to nonstress effects, Journal of Performance of Constructed Facilities, 22(2), 71-82, 2008.

[22] S. Pagliara, I. Carnacina. Temporal scour evolution at bridge piers: effect of wood debris roughness and porosity. Journal of Hydraulic Research, 48(1), 3-13, 2010.

[23] A. Whittaker, R. Hamburger, M. Mahoney, Performance-based engineering of buildings for extreme events, AISC-SINY Symposium on Resisting Blast and Progressive Collapse, pp. 55-66, 2003.

[24] F. Petrini, A. Palmeri, Performance-Based Design of bridge structures subjected to multiple hazards: a review, 6th International Conference on Bridge Maintenance, Safety and Management, pp. 2040-2047, 2012.

[25] M. Barbato, F. Petrini, V.U. Unnikrishnan, M.Ciampoli, Performance-based hurricane engineering (PBHE) framework, Structural Safety, 45, 24-35, 2013. 
[26] C. Manes, M. Brocchini, Local scour around structures and the phenomenology of turbulence. Journal of Fluid Mechanics, 779, 309-324, 2015.

[27] B. Gjunsburgs, G. Jaudzems, J. Govša Hydrograph Shape Impact on the Scour Development with Time at Engineering Structures in River Flow. Construction Science, 11, 6-12, 2010.

[28] P. Todorovic, An Introduction to Stochastic Processes and Their Applications, New York: Springer-Verlag, 1992.

[29] E. Tubaldi, L. Macorini, B. Izzuddin, C. Manes, F. Laio, Probabilistic assessment of scour risk for bridge piers. Under review in Structural Safety, 2017.

[30] A.W. Page, The biaxial compressive strength of brick masonry. Proceedings of the Institution of Civil Engineers, 71,3, 893-906, 1981.

[31] S. Dolarevic, A. Ibrahimbegovic, A modified three-surface elasto-plastic cap model and its numerical implementation. Computers \& Structures, 85(7), 419-430, 2007.

[32] J. Page, Masonry Arch Bridges - State of the Art Review. HMSO, London, 1993.

[33] J. Witzany, T. Cejka, Reliability and failure resistance of the stone bridge structure of Charles Bridge during floods. Journal of civil engineering and management, 13(3), 227236, 2007.

[34] K. Terzaghi, Evaluation of coefficients of subgrade reaction, Geotechnique, 5(4): 41-50, 1955.

[35] G. Gazetas, Foundation Vibrations, in eds. H.Y. Fang, R. Van Nostrand, Foundation Engineering Handbook, New York, New York, pp. 553-593, 1991.

[36] Fema 2000, Prestandard and Commentary for the Seismic Rehabilitation of Buildings, Fema 356, prepared by the American Society of Civil Engineers for Federal Emergency Management Agency, Washington, D.C.

[37] G.A. Jokhio, B.A. Izzuddin, A Dual Super-Element Domain Decomposition Approach for Parallel Nonlinear Finite Element Analysis, International Journal for Computational Methods in Engineering Science and Mechanics, 16(3), 188-212, 2015.

[38] G.A. Jokhio. Mixed dimensional hierarchic partitioned analysis of nonlinear structural systems, PhD Thesis, Imperial College London, 2012.

[39] B.A. Izzuddin, Nonlinear dynamic analysis of framed structures, $\mathrm{PhD}$ thesis, Imperial College of Science and Technology, London, 1991.

[40] J.M. Cunderlik, T.B. Ouarda. Regional flood-duration-frequency modeling in the changing environment. Journal of Hydrology, 318(1), 276-291, 2006.

[41] A. Rodriguez-Villares, E. Minga, L. Macorini, B.A. Izzuddin, An Automation Strategy for Mesoscale Partitioned Analysis of Complex Masonry Structures, in J. Kruis, Y. Tsompanakis, B.H.V. Topping, (Editors), Proceedings of the Fifteenth International Conference on Civil, Structural and Environmental Engineering Computing, CivilComp Press, Stirlingshire, UK, Paper 75, 2015.

[42] G. De Felice, \& S. De Santis, Experimental and numerical response of arch bridge historic masonry under eccentric loading, International Journal of Architectural Heritage, $\mathbf{4}(2), 115-137,2010$. 